Article

\title{
Dynamic Variations in Multiple Bioactive Constituents under Salt Stress Provide Insight into Quality Formation of Licorice
}

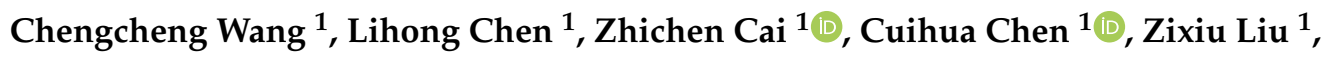 \\ Xunhong Liu ${ }^{1,2,3, *}$, Lisi Zou ${ }^{1}$, Jiali Chen $\left.{ }^{1} \mathbb{(}\right)$, Mengxia Tan ${ }^{1}$, Lifang Wei ${ }^{1}$ and Yuqi Mei ${ }^{1}$ \\ 1 College of Pharmacy, Nanjing University of Chinese Medicine, Nanjing 210023, China; \\ ccw199192@163.com (C.W.); clh_helen@163.com (L.C.); caizhichen2008@126.com (Z.C.); \\ cuihuachen2013@163.com (C.C.); liuzixiu3221@126.com (Z.L.); zlstcm@126.com (L.Z.); \\ 18994986833@163.com (J.C.); 18816250751@163.com (M.T.); weilifang1995@yeah.net (L.W.); \\ 18260028173@163.com (Y.M.) \\ 2 Collaborative Innovation Center of Chinese Medicinal Resources Industrialization, Nanjing 210023, China \\ 3 National and Local Collaborative Engineering Center of Chinese Medicinal Resources Industrialization and \\ Formulae Innovative Medicine, Nanjing 210023, China \\ * Correspondence: liuxunh1959@163.com; Tel./Fax: +86-25-8581-1524
}

Academic Editors: Robert Shellie and Francesco Cacciola

Received: 5 September 2019; Accepted: 10 October 2019; Published: 11 October 2019

\begin{abstract}
The demand for licorice and its natural product derivatives in domestic and foreign market is considerably huge. The core production areas of licorice are covered with salinity and drought land in northwestern China. Studies have shown that suitable environmental stress can promote the accumulation of glycyrrhizin and liquiritin to improve its quality as medicinal materials. However, there are few reports on other bioactive constituents of licorice, not to mention their dynamic accumulation under stressed conditions. To explore the quality formation of licorice from the perspective of salt influence, a reliable method based on ultra-fast liquid chromatography tandem triple quadrupole mass spectrometry (UFLC-MS/MS) was established for simultaneous determination of sixteen bioactive constituents, including triterpenoids, flavonoids, chalcones and their glycosides. Physiological experiments were performed to investigate salt tolerance of licorice under different salinity treatments. The expressions of crucial genes (bAS and CHS), key enzymes of triterpenoid and flavonoid synthesis, were also tested by qRT-PCR. Our study found that $50 \mathrm{mM} \mathrm{NaCl}$ treatment (low stress) was the most favorable to promote the accumulation of bioactive constituents in the long term, without harming the plants. Flavonoid accumulation of non-stressed and low-stressed groups became different in the initial synthesis stage, and glycosyltransferases may have great influence on their downstream synthesis. Furthermore, bAS and CHS also showed higher levels in low-stressed licorice at harvest time. This work provides valuable information on dynamic variations in multiple bioactive constituents in licorice treated by salt and insight into its quality formation under stressed conditions.
\end{abstract}

Keywords: licorice; salt stress; bioactive constituents; UFLC/MS/MS

\section{Introduction}

Licorice is one of the most frequently used herbs across the world. It was originally recorded in Shennong Materia Medica in China [1]. According to traditional Chinese medical theory, licorice can enhance "qi" (a kind of energy), relieve pain, act as an effective antidote [2,3], and it has also been widely applied to treat respiratory infections, gastritis, tremors, and peptic ulcers in folk medicine [4]. At present, people employ ingredients extracted from licorice as food additives, such as a flavoring 
agent in baked goods, frozen dairy products, and beverages [5]. Although there are different ways of using licorice, it is directly or indirectly related to its phytochemicals [6]. However, the quality of licorice on the market is uneven and evidence on its quality formation is scarce, seriously hindering the wide application of clinical and other aspects of licorice. Currently, more than 400 compounds are found in licorice. Triterpenoids and flavonoids take the largest proportion of all chemical compounds and contain the most diverse structure, along with their corresponding glycosides [7-10], which are dominantly responsible for various bioactivities. Therefore, the synthesis and accumulation of triterpenoids and flavonoids are an important aspect for the study of licorice quality formation.

Previous studies have shown that abiotic stress, such as salt or drought stress, significantly influences the contents of glycyrrhizin and several flavonoids in licorice [11,12], illustrating that the planting environment possibly leads to different accumulation of bioactive constituents of licorice, which results in differences in quality. Meanwhile, it is such environmental stress that helps the medicinal plants accumulate secondary metabolites, considering production areas of licorice, covered with salinity and drought land [13-15]. In addition, formation and accumulation of these metabolites is closely related to expression of key enzymes encoded by specific genes in biosynthetic pathways [11]. There are a great number of studies on the quality differences of licorice [16-18]. However, research on how the differences form under stress condition still remains limited. Accordingly, we investigated dynamic variations in multiple bioactive constituents, as well as the expression of rate-limiting enzymes associated with the synthesis of flavonoids and triterpenoids under salt stress.

In the present study, sixteen bioactive constituents, including triterpenoids, flavonoids, chalcones and their glycosides, in licorice under salt stress were chosen to be determined by the valid ultra-fast liquid chromatography tandem triple quadrupole mass spectrometry (UFLC-QTRAP-MS/MS) method. Then we investigated the influence of $\mathrm{NaCl}$ stress on the bioactive constituents in licorice from total accumulative contents, the dynamic changes of bioactive constituent accumulation, and the different synthesis stage of bioactive constituents. Physiological characteristics of antioxidative enzymes such as peroxidase (POD), superoxide dismutase (SOD), glutathione reductase (GR), and catalase (CAT) activities were introduced. Changes of those enzymes were observed in licorice during different stress periods. At the gene level, the differential expressions of crucial genes (bAS and CHS), key enzymes of triterpenoid and flavonoid synthesis, were determined by qRT-PCR as well.

Taken together, we studied dynamic changes of multiple bioactive constituents and their total accumulation in licorice under salt stress for the first time. Combined with the expression of rate-limiting enzymes encoding protein synthase of flavonoids and triterpenoids, our study not only provides valuable information on synthesis and accumulation of bioactive constituents in licorice, but insights of its quality formation research under stressed conditions.

\section{Results and Discussion}

\subsection{Effects of Salt Stress on Phenotype and Antioxidant Enzymes}

The phenotype of the plants was obviously changed by salinity in the first place. In this study, morphological changes were observed in licorice seedlings under different concentrations of $\mathrm{NaCl}$ treatment. Both control $(0 \mathrm{mM} \mathrm{NaCl})$ and severe stress $(200 \mathrm{mM} \mathrm{NaCl})$ groups of seedlings showed weaker development than the other two stressed groups (Figure S1), suggesting licorice may live more vigorously under suitable salt conditions. Apart from growth inhibition, salinity stress also causes ion toxicity at the cellular level $[19,20]$. In order to survive harsh circumstances, plants have developed an efficient defensive strategy to scavenge ROS by producing a series of enzymes such as CAT, SOD, POD, etc. [21]. Besides, evidence indicates that the GR enzyme plays a crucial role in balancing the reduced glutathione/oxidized glutathione (GSH/GSSG) ratio, which participates in ROS scavenging by functioning as a redox buffer under $\mathrm{NaCl}$ stress conditions [22]. Figure 1 shows that the contents of those active enzymes fluctuated in different stressed periods. The POD and GR contents in the control group showed opposite trends to the stress group, indicating that antioxidants were activated in the 
salt-stressed groups, and their anti-stress activity showed a dynamic change. Furthermore, with the extension of stress time (starting from 35 days), the activity of enzymes in the low salt-stressed group $(50 \mathrm{mM} \mathrm{NaCl})$ basically showed slightly higher contents than those of other groups, meaning that salt stress in suitable concentrations had a lasting effect on plants.

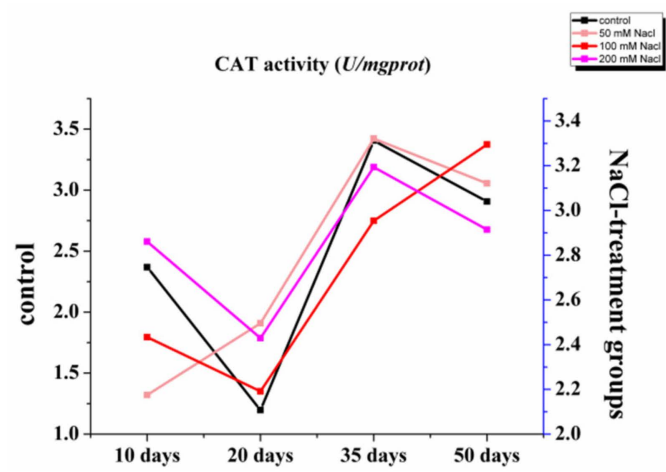

(A)

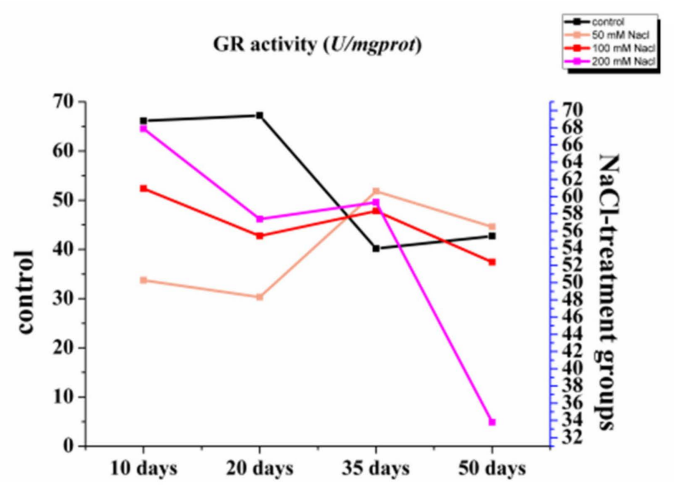

(C)

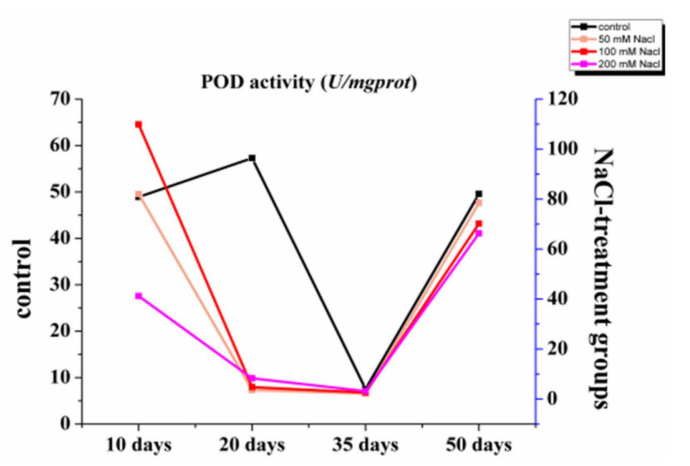

(B)

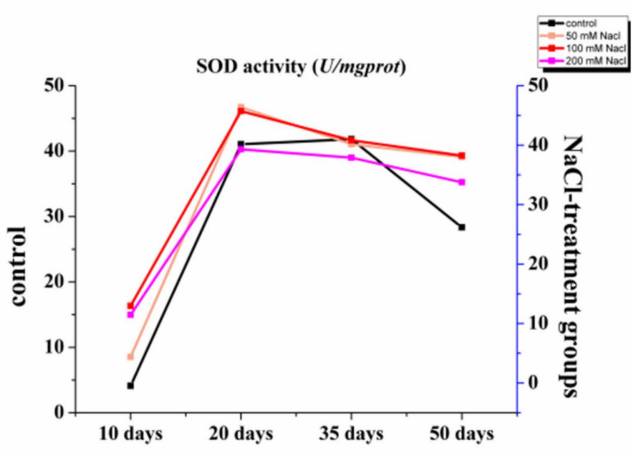

(D)

Figure 1. Dynamic contents of antioxidases CAT (A), GR (B), POD (C), and SOD (D) in all licorice groups of different $\mathrm{NaCl}$ concentrations.

\subsection{Dynamic Variations in Multiple Bioactive Constituents}

\subsubsection{Optimization of UFLC-QTRAP-MS/MS Conditions}

The optimum chromatographic condition was modified according to our previous work [23]. The UFLC system with a XBridge ${ }^{\circledR} C_{18}$ column $(100 \times 4.6 \mathrm{~mm}, 3.5 \mu \mathrm{m})$ was applied. Based on sensitivity and separation, satisfactory UFLC conditions were obtained when eluted with water containing $0.1 \%(\mathrm{v} / \mathrm{v})$ formic acid and acetonitrile at $0.8 \mathrm{~mL} \mathrm{~min}{ }^{-1}$ with a column temperature of $30{ }^{\circ} \mathrm{C}$. MS condition was also studied to obtain the best instrumental conditions. After trial and error inspection, all of the detected chemicals (about $100 \mathrm{ng} / \mathrm{mL}$ ) were injected separately into the electrospray ionization (ESI), and they all showed good condition in the negative ion mode. MRM (multiple reaction monitoring) transition from MS/MS was selected when the most abundant, specific, and stable fragment ions appeared. All of the optimum values for each compound are summarized in Table S1 and the representative extract ion chromatograms of the sixteen analytes with MRM mode are shown in Figure 2. 


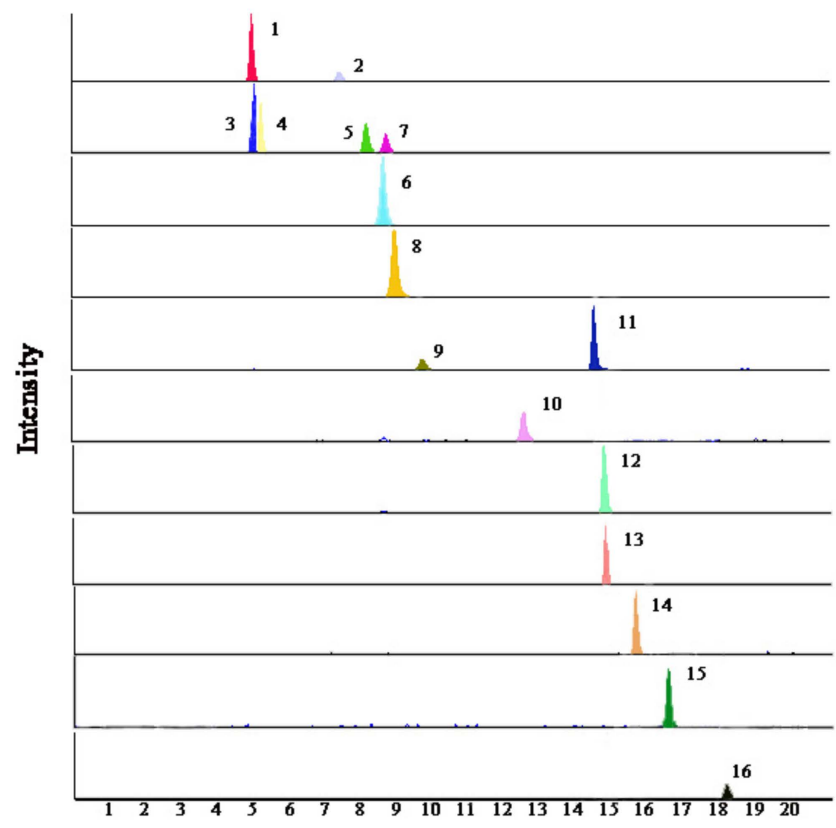

Figure 2. Multiple reaction monitoring (MRM) chromatogram of the sixteen compounds investigated in licorice.

\subsubsection{Method Validation}

Method validation for UFLC/MS/MS analysis was carried out in aspects of linearity, sensitivity (LOD and LOQ), intra- and inter-day precision, repeatability, stability, and recovery test. All analytes showed satisfactory linearity with $r \geq 0.9990$ within wide test ranges. The LODs and LOQs for all analytes ranged from $0.14-2.03 \mathrm{ng} / \mathrm{mL}^{-1}$ and $0.46-6.77 \mathrm{ng} / \mathrm{mL}^{-1}$ of the sixteen analytes, respectively, suggesting high sensitivity of the method. The intra- and inter-day precisions, repeatability, and stability were presented along with RSDs values less than $3.12 \%, 4.41 \%, 3.84 \%$, and $4.17 \%$, respectively. The mean recoveries of all analytes lay between $97.13 \%$ and $106.03 \%$ with a result of RSD values less than $4.35 \%$. The results indicate that the developed method was qualified for quantitative analysis of the targeted compounds. The detailed results are shown in Table 1. 
Table 1. Regression equations, LODs, LOQs, intra- and inter-day precisions, repeatability, stability, and recovery for the 16 compounds.

\begin{tabular}{|c|c|c|c|c|c|c|c|c|c|c|c|c|c|c|}
\hline \multirow[b]{2}{*}{ No } & \multirow[b]{2}{*}{ Name } & \multirow[b]{2}{*}{ CAS No } & \multirow[b]{2}{*}{ Formula } & \multirow{2}{*}{$\begin{array}{c}\text { Regression } \\
\text { Equation }\end{array}$} & \multirow[b]{2}{*}{$\mathbf{r}$} & \multirow{2}{*}{$\begin{array}{l}\text { Linear } \\
\text { Range } \\
\text { (ng/mL) }\end{array}$} & \multirow{2}{*}{$\begin{array}{c}\text { LOD } \\
(\mathrm{ng} / \mathrm{mL})\end{array}$} & \multirow{2}{*}{$\begin{array}{c}\mathrm{LOQ} \\
(\mathrm{ng} / \mathrm{mL})\end{array}$} & \multicolumn{2}{|c|}{ Precision } & \multicolumn{2}{|c|}{ Repeatabiliţtability } & \multicolumn{2}{|c|}{ Recovery } \\
\hline & & & & & & & & & $\begin{array}{c}\text { Intra-day } \\
(\mathrm{RSD} \% ; n=9)\end{array}$ & $\begin{array}{c}\text { Inter-day } \\
(\text { RSD } \% ; n=3)\end{array}$ & $\begin{array}{c}\text { (RSD \%; } \\
n=6)\end{array}$ & $\begin{array}{c}\text { (RSD\%; } \\
n=6)\end{array}$ & $\%$ & RSD $\%$ \\
\hline 1 & liquiritin apioside & 74639-14-8 & $\mathrm{C}_{26} \mathrm{H}_{30} \mathrm{O}_{13}$ & $Y=115 X+127000$ & 0.9997 & $97.7-200,000$ & 0.32 & 1.08 & 2.43 & 3.93 & 2.74 & 3.93 & 101.38 & 3.12 \\
\hline 2 & neoliquiritin & $5088-75-5$ & $\mathrm{C}_{21} \mathrm{H}_{22} \mathrm{O}_{9}$ & $\mathrm{Y}=245 \mathrm{X}+2770$ & 0.9999 & $122-250,000$ & 2.03 & 6.77 & 2.77 & 3.62 & 3.30 & 2.14 & 101.18 & 2.42 \\
\hline 3 & liquiritin & $551-15-5$ & $\mathrm{C}_{21} \mathrm{H}_{22} \mathrm{O}_{9}$ & $Y=359 X+8000$ & 1.0000 & $122-250,000$ & 0.14 & 0.47 & 1.56 & 2.30 & 2.16 & 3.53 & 99.24 & 2.23 \\
\hline 4 & $\begin{array}{l}\text { isoliquiritin } \\
\text { apioside }\end{array}$ & $120926-46-7$ & $\mathrm{C}_{26} \mathrm{H}_{30} \mathrm{O}_{13}$ & $Y=173 X-114000$ & 0.9997 & $97.7-200,000$ & 0.55 & 1.85 & 2.48 & 2.53 & 3.32 & 1.39 & 98.07 & 3.04 \\
\hline 5 & isoliquiritin & $5041-81-6$ & $\mathrm{C}_{21} \mathrm{H}_{22} \mathrm{O}_{9}$ & $Y=605 X-51800$ & 0.9997 & $97.7-100,000$ & 0.22 & 0.74 & 2.70 & 4.41 & 2.55 & 2.80 & 99.13 & 2.39 \\
\hline 6 & ononin & $486-62-4$ & $\mathrm{C}_{22} \mathrm{H}_{22} \mathrm{O}_{9}$ & $Y=329 X+331000$ & 0.9998 & $29.3-60,000$ & 0.14 & 0.46 & 2.03 & 2.76 & 3.67 & 2.19 & 105.00 & 0.35 \\
\hline 7 & neoisoliquiritin & 59122-93-9 & $\mathrm{C}_{21} \mathrm{H}_{22} \mathrm{O}_{9}$ & $\mathrm{Y}=708 \mathrm{X}-13700$ & 0.9999 & $19.5-10,000$ & 0.23 & 0.77 & 2.64 & 3.27 & 3.84 & 3.66 & 101.28 & 2.92 \\
\hline 8 & licochalcone B & $58749-23-8$ & $\mathrm{C}_{16} \mathrm{H}_{14} \mathrm{O}_{5}$ & $Y=315 X-8060$ & 0.9996 & $1.5-3000$ & 0.14 & 0.46 & 2.62 & 3.42 & 2.79 & 2.30 & 98.03 & 3.14 \\
\hline 9 & liquiritigenin & $578-86-9$ & $\mathrm{C}_{15} \mathrm{H}_{12} \mathrm{O}_{4}$ & $Y=688 X-73500$ & 0.9995 & $156.2-20,000$ & 0.25 & 0.82 & 2.85 & 2.53 & 1.84 & 4.17 & 97.41 & 2.02 \\
\hline 10 & echinatin & $34221-41-5$ & $\mathrm{C}_{16} \mathrm{H}_{14} \mathrm{O}_{4}$ & $Y=387 X+275$ & 0.9997 & $0.5-1000$ & 0.14 & 0.46 & 2.94 & 3.50 & 2.06 & 3.29 & 97.58 & 3.21 \\
\hline 11 & isoliquiritigenin & $961-29-5$ & $\mathrm{C}_{15} \mathrm{H}_{12} \mathrm{O}_{4}$ & $Y=1070 X+250000$ & 0.9990 & $29.3-60,000$ & 0.16 & 0.52 & 2.85 & 3.37 & 1.72 & 3.54 & 102.86 & 3.51 \\
\hline 12 & glycyrrhizin & $1405-86-3$ & $\mathrm{C}_{42} \mathrm{H}_{62} \mathrm{O}_{16}$ & $\mathrm{Y}=51.9 \mathrm{X}+913000$ & 0.9990 & $1953-400,000$ & 0.15 & 0.50 & 2.39 & 3.17 & 1.22 & 4.16 & 98.25 & 2.72 \\
\hline 13 & formononetin & $485-72-3$ & $\mathrm{C}_{16} \mathrm{H}_{12} \mathrm{O}_{4}$ & $Y=95 X+20900$ & 1.0000 & $29.3-60,000$ & 0.18 & 0.62 & 2.95 & 3.49 & 2.67 & 2.94 & 97.13 & 4.35 \\
\hline 14 & Licoflavone A & 61153-77-3 & $\mathrm{C}_{20} \mathrm{H}_{18} \mathrm{O}_{4}$ & $Y=863 X-179$ & 0.9991 & $1.56-200$ & 0.13 & 0.43 & 2.80 & 2.95 & 2.79 & 2.15 & 96.83 & 2.61 \\
\hline 15 & Licochalcone A & $58749-22-7$ & $\mathrm{C}_{21} \mathrm{H}_{22} \mathrm{O}_{4}$ & $Y=561 X-556$ & 0.9992 & $1.56-10,000$ & 0.15 & 0.51 & 3.05 & 2.23 & 2.98 & 3.42 & 98.15 & 3.65 \\
\hline 16 & glycyrrhetinic acid & $471-53-4$ & $\mathrm{C}_{30} \mathrm{H}_{46} \mathrm{O}_{4}$ & $\mathrm{Y}=0.0048 \mathrm{X}+67.9$ & 0.9994 & $146-300,000$ & 1.40 & 4.68 & 3.12 & 3.13 & 2.88 & 2.72 & 106.03 & 3.26 \\
\hline
\end{tabular}




\subsubsection{Dynamic Accumulation in Bioactive Constituents}

The validated UFLC-QTRAP-MS/MS method was then employed to comprehensively evaluate bioactive constituents in licorice under different salt treatments. Contents of the sixteen constituents, including triterpenoid saponins and flavonoids, were analyzed. These compounds have been demonstrated to contribute to pharmacological activities and quality evaluation in licorice [24,25]. Figure 3 shows that total amount of bioactive constituents in all groups fluctuated, and accumulation patterns of these constituents in different groups were diverse. The trends of the moderate and severe salt-stressed groups were similar, while the control group suggested opposite results during the later stages. The low salt group showed an overall upward trend, and these results indicate that the environment exerted impact on the dynamic accumulation of bioactive constituents and licorice of the four groups of $\mathrm{NaCl}$ treatments showed different accumulation patterns. Under high salt stress, the accumulation of these constituents in licorice displayed the most fluctuated variations, resulting in damage to the plant homeostasis and unstable accumulation of bioactive constituents.

Based on the different accumulation of bioactive constituents in all groups of licorice, detailed changes about them during 50 days' treatment were also investigated. As shown in Figure 4, the content distribution of the sixteen compounds in each group was similar, suggesting that the environment had little effect on the ratio of these bioactive constituents in non-treated or treated licorice. Among them, the contents of triterpenoid saponins and flavonoid glycosides were the highest in each group. Specifically, the content of glycyrrhizin, glycyrrhetinic acid, and liquiritin apioside took the first three places, followed by flavonoid glycosides such as liquiritin, isoliquiritin apioside, and ononin. In addition, all of the flavonoid aglycones and chalcones stayed at a low level, except for formononetin.
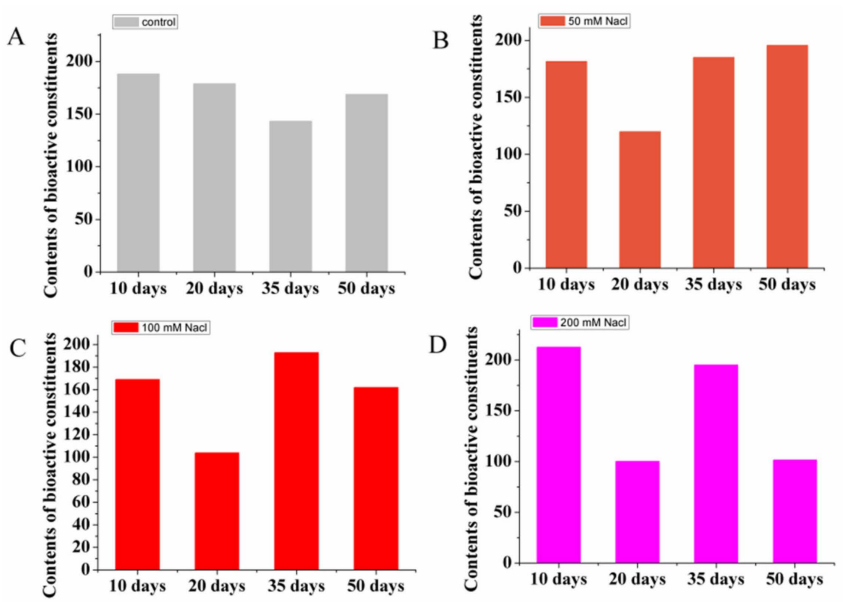

Figure 3. Dynamic accumulation of the total contents of the sixteen compounds. Control group (A). Salt-stressed groups: (B) $50 \mathrm{mM} \mathrm{NaCl}$; (C) $100 \mathrm{mM} \mathrm{NaCl}$; (D) $200 \mathrm{mM} \mathrm{NaCl}$.

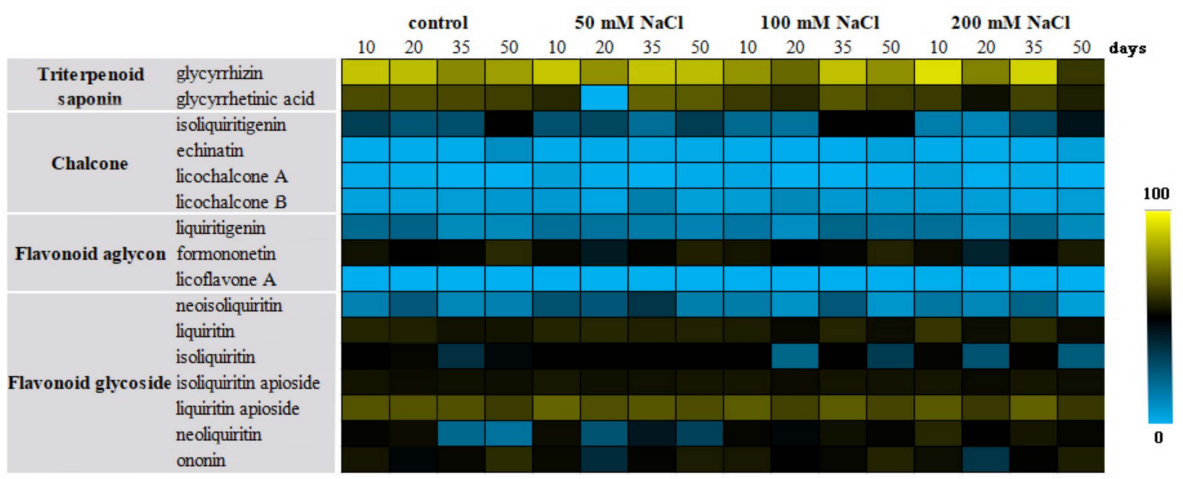

Figure 4. Heat map of the sixteen compounds during 50 days in different groups. 


\subsubsection{Dynamic Distribution Patterns of Bioactive Constituents}

Overall, there is a difference in the total amount of the sixteen bioactive constituents among the stressed and non-stressed groups, indicating that different concentrations of $\mathrm{NaCl}$ significantly affected the accumulation of bioactive constituents in licorice (Figure 5). In terms of glycyrrhizin and glycyrrhetinic acid, the total accumulation of them was found with the highest content in the severe-salt and low-salt groups, and the middle-salt group showed the lowest level. In each group, the contents of bioactive constituents on the same synthesis pathway displayed a similar change trend, such as glycyrrhizin and glycyrrhetinic acid, liquiritin apioside and isoliquiritin apioside, and ononin and formononetin, which means that the accumulation of pathway-related constituents interacted with each other. Considering the results of the total contents of bioactive constituents, strengthening the degree of stress could be a wise strategy in the short term. However, in the long run, salinity treatment with $50 \mathrm{mM} \mathrm{NaCl}$ could better increase the accumulation of bioactive constituents without harming the plants.
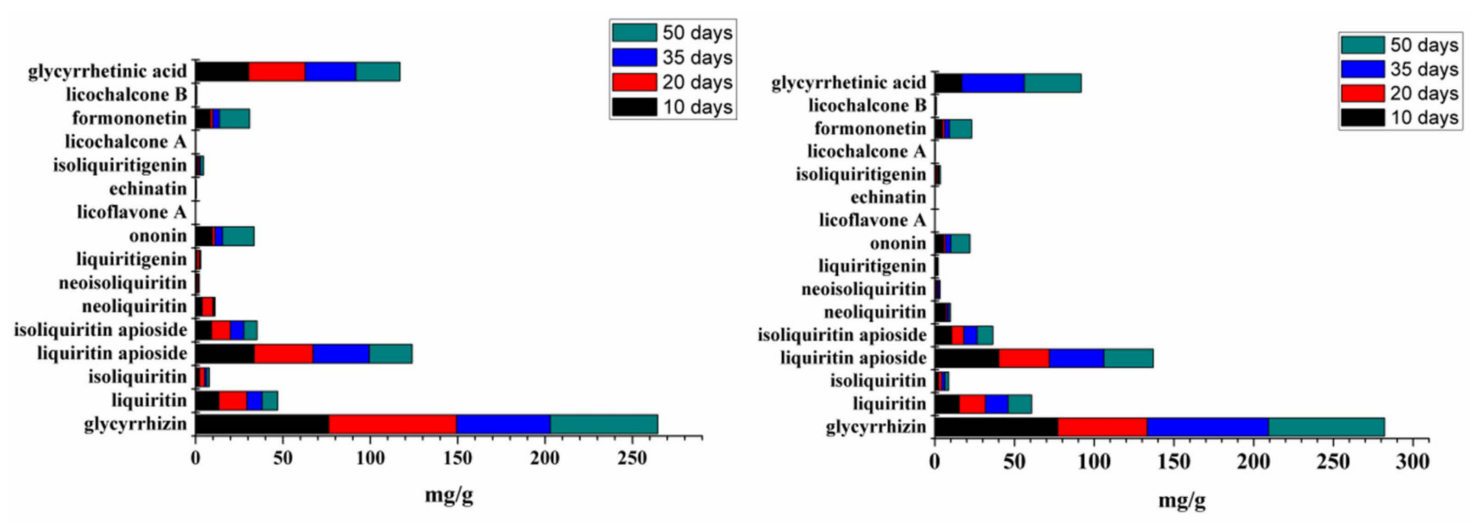

(A)

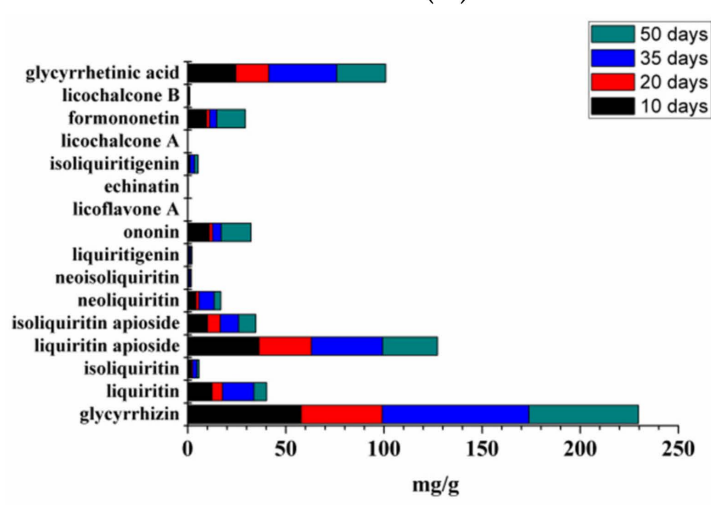

(C)
(B)

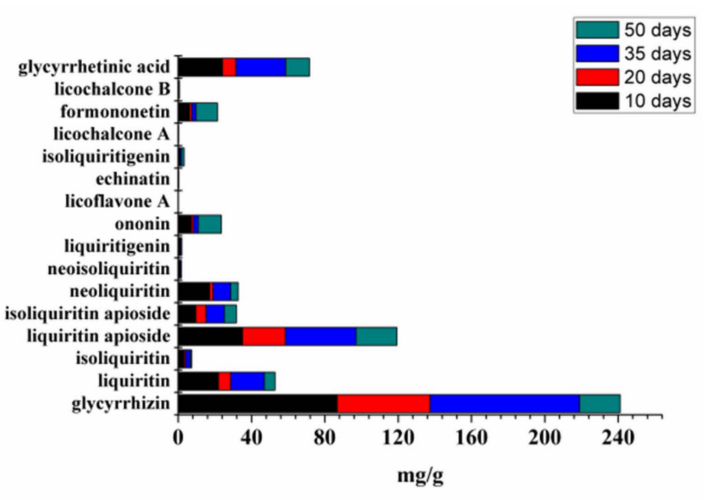

(D)

Figure 5. Accumulative contents of the sixteen compounds in different times: (A) control group; (B) $50 \mathrm{mM} \mathrm{NaCl}$; (C) $100 \mathrm{mM} \mathrm{NaCl}$; (D) $200 \mathrm{mM} \mathrm{NaCl}$.

\subsubsection{Comparison of Dynamic Accumulation in Flavonoids and Triterpenoids}

According to the harvest period (i.e., after 50 days), plant growth status, and accumulation of bioactive constituents, the low-salt group was chosen for comparison with the non-stressed group for further study. Beginning with triterpenoid saponin, similar changes were observed in both groups, probably because glycyrrhetinic acid is a precursor of glycyrrhizin synthesis (Figure 6A,B) [26,27]. Specifically, the control group of triterpenoid saponin displayed an overall downward trend, and the low-salt group fluctuated, but eventually the low-salt group accumulated more of these two triterpenoids. Chalcone is the initial stage of flavonoid synthesis [28]. It can be seen form 
Figure $6 \mathrm{C}, \mathrm{D}$ that the two groups have opposite trends, indicating that the accumulation of flavonoids became different in the initial synthesis. Flavonoid aglycones are represented by liquiritigenin, which is one of the key compounds in the synthesis of other flavonoids. At this stage, the content of liquiritigenin in both groups of licorices showed a falling trend (Figure $6 \mathrm{E}, \mathrm{F}$ ). Similar to chalcone, the total amount of the flavonoid aglycone in the control group was also slightly higher than that of the low-salt group. In the downstream of flavonoid synthesis, flavonoid glycosides are a class of constituents with high content, as well as more bioactivity studies in licorice. Their synthesis is involved in various glycosyltransferases $[29,30]$, which are responsible for various kinds of synthesis of glycosides, including liquiritin and glycyrrhizin. These glycosyltransferases may play an important role in the late synthesis step. Figure $6 \mathrm{G}, \mathrm{H}$ suggests that the changes in the content of flavonoid glycoside in the two groups are basically similar but not entirely the same. The total content of flavonoid glycosides in the stressed group was higher than those in the non-stressed licorice group, suggesting that the bioactive constituents ultimately showed different accumulation in the two groups probably due to synthetic pathways and the effects of the involved synthetase.

\subsection{Differential Expression Analysis of Key Enzymes in Flavonoid and Triterpenoid Biosynthesis}

RT-PCR was performed for two crucial genes (bAS and CHS), encoding rate-limiting enzymes of glycyrrhizin and flavonoid biosynthesis pathways [31,32]. Figure 7 illustrates that their expressions also have different fluctuation degrees after salt treatments. In the short term, the expressions of bAS and CHS were higher in the high salt-stressed group, and the low salt-stressed group was on the rise during the stressed period. The expressions of two genes in the moderate salt-stressed group were the worst, especially in the level of CHS, which was lower than the control group. As for bAS, its expression in all of the stressed groups displayed higher than those in the non-stressed group, and the total expression level was far greater than $\mathrm{CHS}$, indicating that the saline environment significantly enhanced expression levels of these two key genes, particularly in respect to bAS. It is worth noting that the expression levels of bAS and CHS displayed highest in the low-stressed group at harvest time (after 50 days). Combined with the accumulation of bioactive constituents, the findings indicate that suitable salt stress could significantly affect the synthesis of flavonoids and glycyrrhizin. 


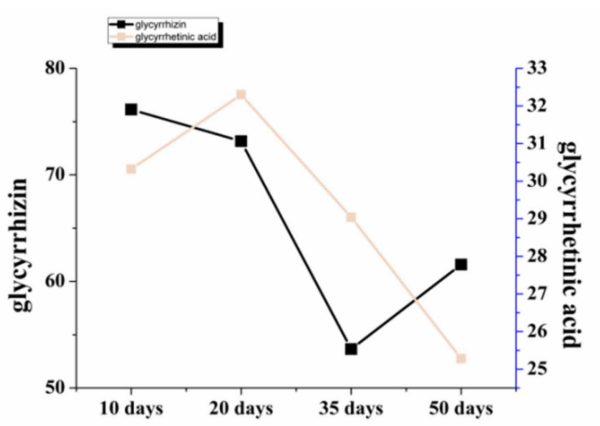

(A)

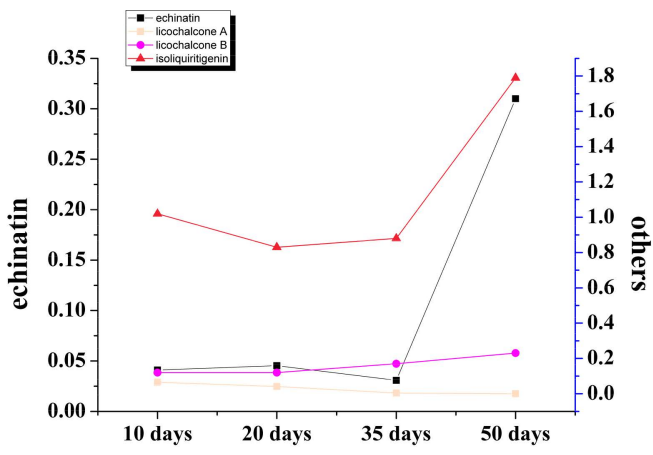

(C)

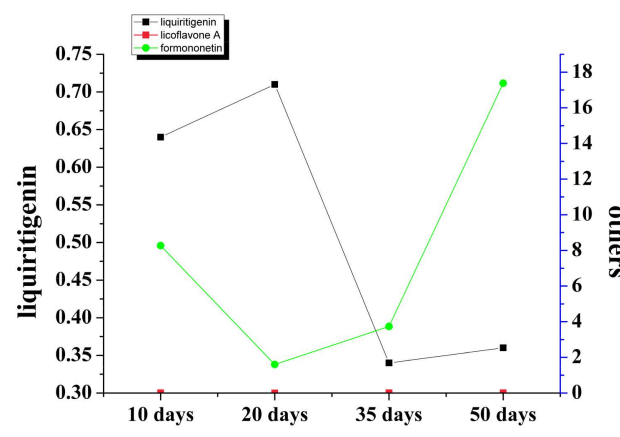

(E)

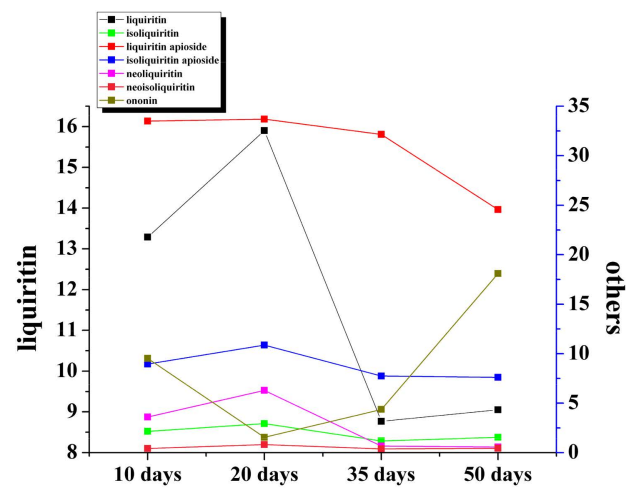

(G)

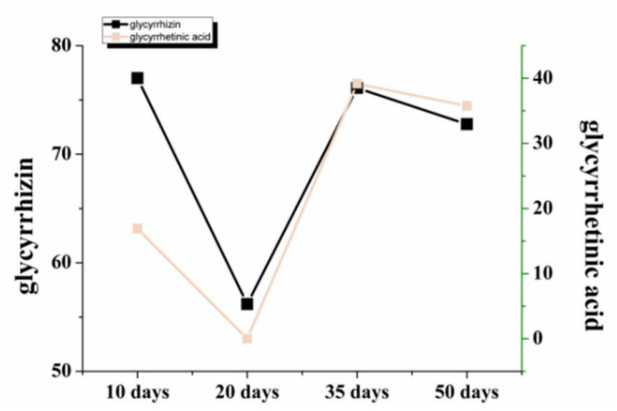

(B)

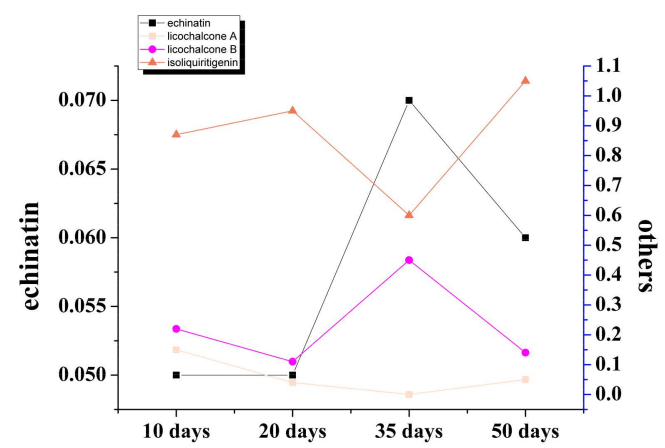

(D)

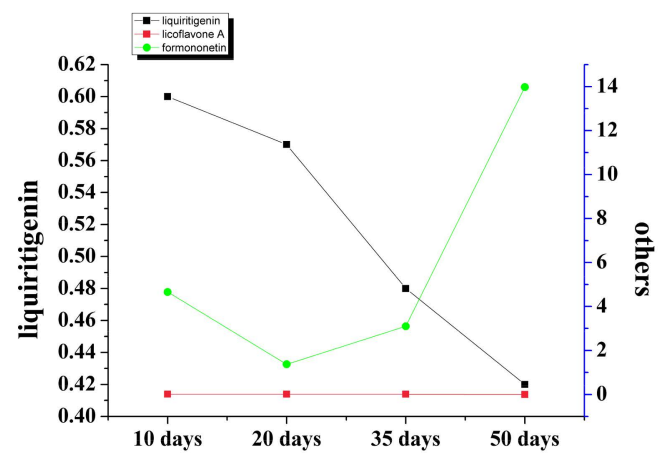

(F)

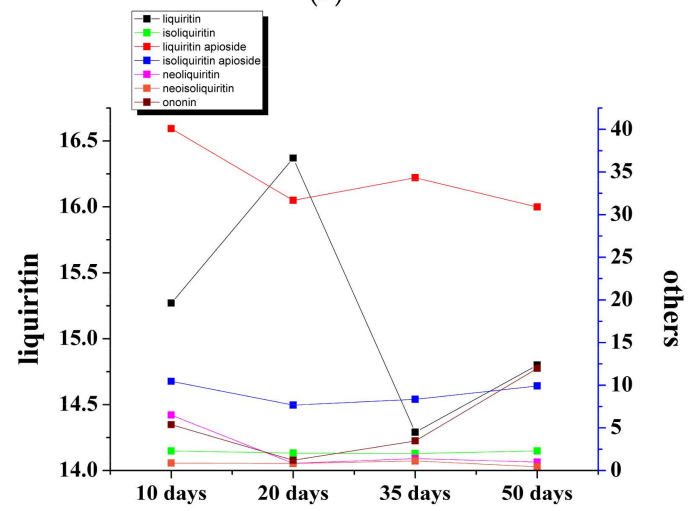

(H)

Figure 6. Dynamic changes of triterpenoid contents, chalcone contents, flavonoid aglycon contents and flavonoid glycoside contents in the control (A,C,E,G) and low-salt (B,D,F,H) groups. 


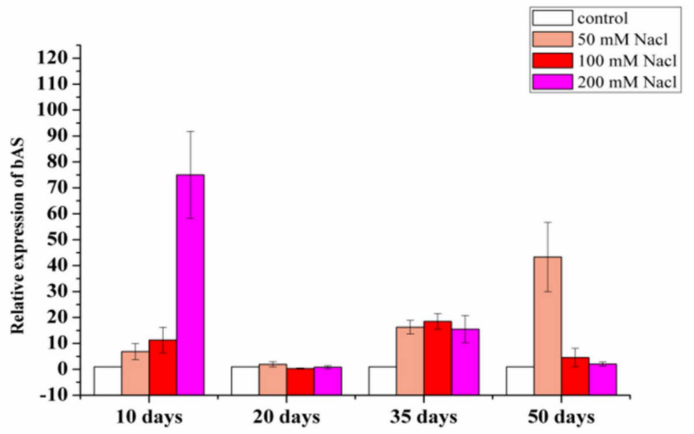

(A)

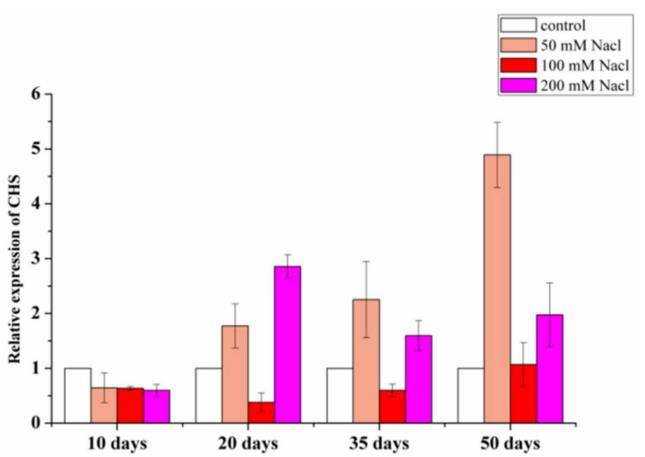

(B)

Figure 7. Dynamic changes of bAS and CHS expressions in control (A) and low-salt (B) groups.

\section{Materials and Methods}

\subsection{Plant Materials and Salinity Treatments}

The one-year-old licorice cultivars, botanically originated from Glycyrrhiza uralensis Fisch, were collected from Yanchi County, Ningxia Province, China. The plants of these licorice seedlings with close diameter and numbers of bud were selected for study. They were planted in the Medicinal Botanical Garden of Nanjing University of Traditional Chinese Medicine (latitude $118^{\circ} 57^{\prime} 1^{\prime \prime}$, east longitude $32^{\circ} 6^{\prime} 5^{\prime \prime}$ ) under a shelter of transparent film blocking off rainwater. Other conditions were almost equivalent to open air. Two seedlings of licorice were planted in one pot (height $50 \mathrm{~cm}$, top diameter $30 \mathrm{~cm}$, bottom diameter $25 \mathrm{~cm}$ ) with approximately $25 \mathrm{~kg}$ dry soil.

Experimental licorice were allowed to grow naturally until they were alive and germinated. Four levels of salt concentrations were then designed as follows: $0 \mathrm{mM}$ (control group), $50 \mathrm{mM}$ (low stress), $100 \mathrm{mM}$ (moderate stress), and $200 \mathrm{mM}$ (severe stress). $\mathrm{NaCl}$ treatments were conducted with 4 replicates at each concentration level. In order to avoid osmotic shock, the concentrations of salt increased gradually until the designated concentrations were reached. The whole period of stress lasted 50 days. Ultimately, experimental samples were harvested, cleaned with PBS, and quickly frozen with liquid nitrogen for subsequent experiments, including physiological assay, quantitative analysis, and the rest were collected as the voucher specimens.

\subsection{Physiological Experiment}

Fresh leaves of licorice under different concentrations of salt treatment were weighed (approximately $0.5 \mathrm{~g}$ ) and ground with liquid nitrogen. The powder was mixed with $4.5 \mathrm{~mL}$ of $0.1 \mathrm{~mol} / \mathrm{L}$ PBS (PH7.4) and the mixture was centrifuged at $3500 \mathrm{rpm}$ for $10 \mathrm{~min}$. The supernatant was collected as the crude enzyme extract. SOD activity was measured according to the hydroxylamine method, POD activity was determined by the colorimetric method, and GR activity was determined by the method of Schaedle and Bassham. CAT activity was assayed in light with the ammonium molybdate method [19,33]. All of the experiments were carried out by assay kits obtained from Nanjing Jiancheng Bioengineering Institute (Nanjing, China), and $200 \mu \mathrm{L}$ of each reaction solution was detected under UV-visible absorptions by a multi-mode microplate reader (SpectraMax M5, San Jose, CA, USA).

\subsection{Multiple Bioactive Constituents Assay}

\subsubsection{Chemicals and Reagents}

Reference compounds of the sixteen chemicals of liquiritin apioside (1) and isoliquiritin apioside (4) were purchased from Nanjing Jingzhu Bio-technology Co., Ltd. (Nanjing, PR China); neoliquiritin (2), ononin (6), licochalcone B (8), isoliquiritigenin (11), glycyrrhizin (12), formononetin (13), and licoflavone A (14) were acquired from Chengdu Chroma-Biotechnology Co., Ltd. (Chengdu, PR China); liquiritin 
(3), liquiritigenin (9), echinatin (10), licochalcone A (15), and glycyrrhetinic acid (16) were obtained from Liangwei Chemical Reagent Co., Ltd. (Nanjing, PR China); isoliquiritin (5) and neoisoliquiritin (7) were offered by Chengdu Purechem-Standard Co., Ltd. (Chengdu, PR China). The purities of all chemical standards were greater than $98 \%$ by HPLC analysis. Ultra-pure water was prepared by a Milli-Q purifying system (Millipore, Bedford, MA, USA). Methanol and acetonitrile of HPLC grade were purchased from Merck (Damstadt, Germany). All other chemicals used in the experiments were of analytical reagent grade (Shanghai Yuanye-Biotechnology Co., Ltd., PR China).

\subsubsection{Sample and Standard Solutions Preparation}

Samples of all groups were harvested and naturally dried. After passing through a 60-mesh sieve, approximately $0.5 \mathrm{~g}$ of each sample powder was accurately weighed and ultrasonically extracted in $25 \mathrm{~mL} \mathrm{70 \%} \mathrm{methanol} \mathrm{for} 1 \mathrm{~h}$. After cooling down at room temperature, the mixture was supplemented with $70 \%$ methanol to compensate for the lost weight, and subsequently centrifuged at 12,000 rpm for $10 \mathrm{~min}$. The supernatant was collected, diluted tenfold, filtered through $0.22 \mu \mathrm{m}$ membrane (Jinteng laboratory equipment Co., Ltd., Tianjin, China), and stored at $4{ }^{\circ} \mathrm{C}$ prior to UFLC-QTRAP-MS/MS analysis.

The sixteen reference compounds were prepared by completely dissolving in methanol, and their concentrations were as follows: (1) $1.060 \mathrm{mg} / \mathrm{mL}$; (2) $1.175 \mathrm{mg} / \mathrm{mL}$; (3) $5.290 \mathrm{mg} / \mathrm{mL}$; (4) $5.130 \mathrm{mg} / \mathrm{mL}$; (5) $1.088 \mathrm{mg} / \mathrm{mL}$; (6) $5.220 \mathrm{mg} / \mathrm{mL}$; (7) $1.190 \mathrm{mg} / \mathrm{mL}$; (8) $1.160 \mathrm{mg} / \mathrm{mL}$; (9) $1.930 \mathrm{mg} / \mathrm{mL}$; (10) $1.120 \mathrm{mg} / \mathrm{mL}$; (11) $0.9600 \mathrm{mg} / \mathrm{mL}$; (12) $10.05 \mathrm{mg} / \mathrm{mL}$; (13) $1.330 \mathrm{mg} / \mathrm{mL}$; (14) $1.010 \mathrm{mg} / \mathrm{mL}$; (15) $0.950 \mathrm{mg} / \mathrm{mL}$; (16) $5.710 \mathrm{mg} / \mathrm{mL}$. This solution was further diluted with methanol for the establishment of the calibration curves. All of the solutions were stored at $4{ }^{\circ} \mathrm{C}$ before analysis.

\subsubsection{Chromatographic and Mass Spectrometric Conditions}

The mobile phase was composed of acetonitrile (A) and $0.1 \%$ aqueous formic acid (B, v/v) with a linear gradient program: $0-4 \mathrm{~min}: 2 \% \mathrm{~B}$; $4-6 \mathrm{~min}: 2-20 \% \mathrm{~B} ; 6-9 \mathrm{~min}: 20-25 \% \mathrm{~B}$; $9-10 \mathrm{~min}: 25-35 \% \mathrm{~B}$; 10-12 min: $35 \%$ B; $12-15$ min: $35-98 \%$ B; $15-16$ min: $98-2 \%$ B; $16-20$ min: $2 \%$ B. The flow rate was kept at $0.8 \mathrm{~mL} \mathrm{~min}^{-1}$ and the column temperature was maintained at $35^{\circ} \mathrm{C}$. The injection volume of the sample was $2 \mu \mathrm{L}$.

A triple quadrupole-linear ion trap mass spectrometer (QTRAP 5500) (AB Sciex, Framingham, MA, USA), equipped with an electrospray ionization (ESI) source, operated in the negative ion mode. The MS parameters were set as follows: GSI flow, $65 \mathrm{~L} \mathrm{~min}^{-1}$; CUR flow, $30 \mathrm{~L} \mathrm{~min}^{-1}$; gas temperature, $550{ }^{\circ} \mathrm{C}$; pressure of nebulizer of MS, $5500 \mathrm{~V}$ (positive) and $-4500 \mathrm{~V}$ (negative). To ensure mass accuracy and reproducibility, all MS data were acquired by the Analyst 1.6 .3 software. The cone voltage and collision energy parameter of each compound were individually optimized to ensure mass accuracy and reproducibility.

\subsubsection{Method Validation and Sample Determination}

The developed analysis method was validated for the linearity by the construction of calibration curves of each analyte. The limit of detection (LOD) and limit of quantitation (LOQ) were determined using a series of diluted standard solutions until the signal-to-noise $(\mathrm{S} / \mathrm{N})$ ratio was about 10 and 3 , respectively. To evaluate accuracy, a recovery test was conducted by standard protocol and calculated by the formula: Recovery $(\%)=($ found amount - original amount $) /$ spiked amount $\times 100 \%$ [17] . To confirm the repeatability, six independent sample solutions from the same batch were processed in parallel and analyzed. As for precision, six replicate injections of mixed standard solution were analyzed within one day, and nine replicates on three consecutive days. Stability was achieved by analyzing the same sample solution, stored at room temperature at $0,2,4,8,12$, and $24 \mathrm{~h}$ [34]. Relative standard deviations (RSD\%) were taken as measurements for all of the variations. The quantitative determination of the bioactive constituents of licorice was performed under the optimal condition by QTRAP 5500. 


\subsection{Quantitative Real-Time PCR}

We selected two genes (bAS and CHS) for quantitative real-time PCR (qRT-PCR) analysis, whose counterpart proteins are key enzymes in the biosynthesis of glycyrrhizin and flavonoid. The qRT-PCR reactions were carried out with a Trizol Total RNA Isolation Kit (Sangon Biotech, Shanghai, China) according to the protocols. cDNA pools for qRT-PCR from the total RNA were synthesized using HiScript Q RT SuperMix for qPCR (Vazyme Biotech Co.,Ltd, Nanjing, China). The primers were designed using Primer 3.0 softwaree (http://bioinfo.ut.ee/primer3-0.4.0/). The reference gene used $\beta$-actin. The relative expression level of genes was calculated using a real-time PCR system (ABI 7500 Real-Time PCR System) based on the $2^{-\Delta \Delta C t}$ method. Primers for RT-qPCR are listed in Table S2.

\subsection{Data Processing}

UFLC/MS/MS data were acquired and analyzed by the Analyst 1.6.2 software. The bars, lines, and charts were charted by Origin pro 8 (Origin Lab, Massachusetts, USA). The mean values and standard deviation of all parameters were calculated by the measurements of four replicates.

\section{Conclusions}

Our study investigated the effects of salt stress on the bioactive constituents in licorice from three perspectives, including total accumulative contents, the dynamic changes of accumulation, and the different synthesis stages of bioactive constituents. The results showed that the categories and content ratio of bioactive constituents in each group were similar, meaning that the environmental impact did not dominate the distribution patterns of bioactive constituents in licorice, but the total amount of them in each group was different, suggesting salt stress indeed affected their accumulation. Specifically, more of glycyrrhetinic acid and glycyrrhizin were found in the salt stress groups, even if these two triterpenoids showed similar trends in both stressed and non-stressed licorice. The accumulation of flavonoids became different between stressed and non-stressed groups at the beginning of synthesis, and glycosyltransferases probably had great contribution to the accumulation of flavonoid glycosides, as well as glycyrrhizin. Furthermore, the low salt-stressed licorice performed best in expression levels of bAS and CHS. It also accumulated more bioactive constituents at harvest time. Severe stressed conditions can rapidly stimulate the increase of bioactive constituents and gene levels in a short stressed period, but it is not conducive to the growth of licorice. Thus, we believe $50 \mathrm{mM} \mathrm{NaCl}$ would be the best choice to breed licorice in the long run. Our work investigated dynamic variations in multiple bioactive constituents under salt stress and provided novel clues for the quality formation of licorice.

Supplementary Materials: The Supplementary Materials are available online.

Author Contributions: C.W. and X.L. conceived and designed the experiments. L.C., Z.C., and C.C. performed the experiments. Z.L., L.Z., J.C., M.T., L.W., and Y.M. analyzed the data and drafted the manuscript. All authors contributed to the revision of this manuscript and approved the final manuscript.

Funding: This study was financially supported by National Key R\&D Program of China (2018YFC1706500).

Conflicts of Interest: The authors declare no conflicts of interest.

\section{References}

1. Wang, L.; Yang, R.; Yuan, B.; Liu, Y.; Liu, C. The antiviral and antimicrobial activities of licorice, a widely-used Chinese herb. Acta Pharm. Sin. B 2015, 5, 310-315. [CrossRef] [PubMed]

2. Liu, Y.; Zhu, X.Q.; Li, W.D.; Wen, H.; Liu, C.S. Enhancing ergosterol production in Pichia pastoris GS115 by overexpressing squalene synthase gene from Glycyrrhiza uralensis. Chin. J. Nat. Med. 2015, 13, 338-345. [CrossRef]

3. Chinese Pharmacopoeia Commission. Pharmacopoeia of the People's Repulic of China. Part I; Chemical Industry Press: Beijing, China, 2015; p. 86. 
4. Wang, X.; Zhang, H.; Chen, L.; Shan, L.; Fan, G.; Gao, X. Liquorice, aunique "guide drug" of traditional Chinese medicine: A review of its role in drug interactions. J. Ethnopharmacol. 2013, 150, 781-790. [CrossRef] [PubMed]

5. Nassiri-asl, M.; Hosseinzadeh, H. Licorice (Glycyrrhiza species). In Genetic Resources, Chromosome Engineering, and Crop Improvement: Medicinal Plants, Volume 6; Singh, R.J., Ed.; CRC Press: Boca Raton, FL, USA, 2012; pp. 935-958.

6. Xiang, C.; Qiao, X.; Ye, M.; Guo, D.A. Classification and distribution analysis of constituents in Glycyrrhiza using licorice compounds database. Acta Pharm. Sin. 2012, 47, 1023-1030.

7. Zhang, M.T.; Wang, B.; Jia, Y.N.; Liu, N.; Ma, P.S.; Gong, S.S.; Niu, Y.; Sun, T.; Li, Y.X.; Yu, J.Q. Neuroprotective effect of liquiritin against neuropathic pain induced by chronic constriction injury of the sciatic nerve in mice. Biomed. Pharmacother. 2017, 95, 186-198. [CrossRef]

8. Li, K.; Ji, S.; Song, W.; Kuang, Y.; Lin, Y.; Tang, S.; Cui, Z.; Qiao, X.; Yu, S.; Ye, M. Glycybridins A-K, Bioactive Phenolic Compounds from Glycyrrhiza glabra. J. Nat. Prod. 2017, 80, 334-346. [CrossRef] [PubMed]

9. Wang, Q.E.; Lee, F.S.; Wang, X. Isolation and purification of inflacoumarin A and licochalcone A from licorice by high-speed counter-current chromatography. J. Chromatogr. A 2004, 1048, 51-57. [CrossRef]

10. Gao, X.; Wang, W.; Wei, S.; Li, W. Review of pharmacological effects of Glycyrrhiza radix and its bioactive compounds. Zhongguo Zhong Yao Za Zhi 2009, 34, 2695-2700.

11. Yu, F.; Wang, Q.; Wei, S.; Wang, D.; Fang, Y.; Liu, F.; Zhao, Z.; Hou, J.; Wang, W. Effect of genotype and environment on five bioactive constituents of cultivated licorice (Glycyrrhiza uralensis) populations in northern China. Biol. Pharm. Bull. 2015, 38, 75-81. [CrossRef]

12. Nasrollahi, V.; Mirzaie-asl, A.; Piri, K.; Nazeri, S.; Mehrabi, R. The effect of drought stress on expression of key genes involved in biosynthesis of triterpenoid saponins in licorice (Glycyrrhiza glabra). Phytochemistry 2014, 103, 32-37. [CrossRef]

13. Golldack, D.; Li, C.; Mohan, H.; Probst, N. Tolerance to drought and salt stress in plants: Unraveling the signaling networks. Front. Plant Sci. 2014, 5, 151-161. [CrossRef] [PubMed]

14. Gao, X.J.; Zhao, D.; Zhao, J.J.; Zhang, X.; Wang, Y.H.; Wang, H.Q. Herbal Textural Research on Glycyrrhizae Radix et Rhizoma. Chin. J. Exp. Tradit. Med. Formulae 2017, 23, 193-198.

15. Brunetti, C.; George, R.M.; Tattini, M.; Field, K.; Davey, M.P. Metabolomics in plant environmental physiology. J. Exp. Bot. 2013, 64, 4011-4020. [CrossRef] [PubMed]

16. Rizzato, G.; Scalabrin, E.; Radaelli, M.; Capodaglio, G.; Piccolo, O. A new exploration of licorice metabolome. Food Chem. 2017, 221, 959-968. [CrossRef] [PubMed]

17. Jiang, Z.; Wang, Y.; Zheng, Y.; Yang, J.; Zhang, L. Ultra high performance liquid chromatography coupled with triple quadrupole mass spectrometry and chemometric analysis of licorice based on the simultaneous determination of saponins and flavonoids. J. Sep. Sci. 2016, 39, 2928-2940. [CrossRef] [PubMed]

18. Zhu, Z.; Tao, W.; Li, J.; Guo, S.; Qian, D.; Shang, E.; Su, S.; Duan, J.A. Rapid determination of flavonoids in licorice and comparison of three licorice species. J. Sep. Sci. 2016, 39, 473-482. [CrossRef] [PubMed]

19. Chen, C.H.; Wang, C.C.; Liu, Z.X.; Liu, X.H.; Zou, L.S.; Shi, J.J.; Chen, S.Y.; Chen, J.L.; Tan, M.X. Variations in Physiology and Multiple Bioactive Constituents under Salt Stress Provide Insight into the Quality Evaluation of Apocyni Veneti Folium. Int. J. Mol. Sci. 2018, 5, 3042. [CrossRef]

20. Hua, Y.; Wang, S.; Liu, Z.; Liu, X.; Zou, L.; Gu, W.; Hou, Y.; Ma, Y.; Luo, Y.; Liu, J. iTRAQ-based quantitative proteomic analysis of cultivated Pseudostellaria heterophylla and its wild-type. J. Proteom. 2016, 29, 13-25. [CrossRef]

21. Sabarni, B.; Asok, K.B. Sodium chloride primed seeds modulate glutathione metabolism in legume cultivars under $\mathrm{NaCl}$ stress. Am. J. Plant Physiol. 2018, 13, 8-22.

22. Singh, M.; Singh, V.P.; Prasad, S.M. Nitrogen alleviates salinity toxicity in Solanum lycopersicum seedlings by regulating ROS homeostasis. Plant Physiol. Biochem. 2019, 141, 466-476. [CrossRef]

23. Wang, C.C.; Cai, H.; Zhao, H.; Yan, Y.; Shi, J.J.; Chen, S.Y.; Tan, M.X.; Chen, J.L.; Zou, L.S.; Chen, C.H.; et al. Distribution patterns for metabolites in medicinal parts of wild and cultivated licorice. J. Pharm. Biomed. Anal. 2018, 30, 464-473. [CrossRef] [PubMed]

24. Tang, Z.H.; Li, T.; Tong, Y.G.; Chen, X.J.; Chen, X.P.; Wang, Y.T.; Lu, J.J. A systematic review of the anticancer properties of compounds isolated from Licorice (Gancao). Planta Med. 2015, 81, 1670-1687. [CrossRef] [PubMed] 
25. Zhang, H.Z.; Xiao, X.H.; Wang, J.B.; Wang, J. Consistency of efficacy-equivalent: Key essential point of quality control for Chinese materia medica. Chin. Tradit. Herb. Drugs 2015, 46, 1571-1575.

26. Seki, H.; Sawai, S.; Ohyama, K.; Mizutani, M.; Ohnishi, T.; Sudo, H.; Fukushima, E.O.; Akashi, T.; Aoki, T.; Saito, K.; et al. Triterpene Functional Genomics in Licorice for Identifification of CYP72A154 Involved in the Biosynthesis of Glycyrrhizin. Plant Cell 2011, 23, 4112-4123. [CrossRef] [PubMed]

27. Xu, G.; Cai, W.; Gao, W.; Liu, C. novel glucuronosyltransferase has an unprecedented ability to catalyse continuous two-step glucuronosylation of glycyrrhetinic acid to yield glycyrrhizin. New Phytol. 2016, 212, 123-135. [CrossRef] [PubMed]

28. Xu, H.; Park, N.I.; Li, X.; Kim, Y.K.; Lee, S.Y.; Park, S.U. Molecular cloning and characterization of phenylalanine ammonia-lyase, cinnamate 4-hydroxylase and genes involved in flavone biosynthesis in Scutellaria baicalensis. Bioresour. Technol. 2010, 101, 9715-9722. [CrossRef]

29. Seki, H.; Tamura, K.; Muranaka, T. P450s and UGTs: Key players in the structural diversity of triterpenoid saponins. Plant Cell Physiol. 2015, 56, 1463-1471. [CrossRef]

30. Yonekura-Sakakibara, K.; Hanada, K. An evolutionary view of functional diversity in family 1 glycosyltransferases. Plant J. 2011, 66, 182-193. [CrossRef]

31. Seki, H.; Ohyama, K.; Sawai, S.; Mizutani, M.; Ohnishi, T.; Sudo, H.; Akashi, T.; Aoki, T.; Saito, K.; Muranaka, T. Licorice beta-amyrin 11-oxidase, a cytochrome P450 with a key role in the biosynthesis of the triterpene sweetener glycyrrhizin. Proc. Natl. Acad. Sci. USA 2008, 105, 14204-14209. [CrossRef]

32. Mamati, G.E.; Liang, Y.R.; Lu, J.L. Expression of basic genes involved in tea polyphenol synthesis in relation to accumulation of catechins and total tea polyphenols. J. Sci. Food Agric. 2006, 86, 459-464. [CrossRef]

33. Schaedle, M.; Bassham, J.A. Chloroplast glutathione reductase. Plant Physiol. 1977, 59, 1011-1012. [CrossRef] [PubMed]

34. Song, W.; Qiao, X.; Chen, K.; Wang, Y.; Ji, S.; Feng, J.; Li, K.; Lin, Y.; Ye, M. Biosynthesis-based quantitative analysis of 151 secondary metabolites of licorice to differentiate medicinal Glycyrrhiza species and their hybrids. Anal. Chem. 2017, 89, 3146-3153. [CrossRef] [PubMed]

Sample Availability: Samples of the compounds are available from the authors.

(C) 2019 by the authors. Licensee MDPI, Basel, Switzerland. This article is an open access article distributed under the terms and conditions of the Creative Commons Attribution (CC BY) license (http://creativecommons.org/licenses/by/4.0/). 